\title{
Evolución y desarrollo legislativo del cooperativismo en Colombia desde 1991*
}

\section{Evolution and legislative development of cooperativism in Colombia since 1991}

\author{
LUZ KARIME ÁNGEL ${ }^{* *}$ \\ Daniel Alfonso Barragán Ronderos ${ }^{* *}$
}

${ }^{\star}$ Este artículo de revisión se deriva de la primera fase del desarrollo del proyecto de investigación Cooperativismo. Ámbito de actuación para el desarrollo socioeconómico en Colombia”,

**Abogada, Doctor en Derecho, Magister en Derecho Comercial Internacional, especialista en Pedagogía y docencia universitaria, docente investigador de la Universidad La Gran Colombia. E-mail: Iuz.angel@ugc.edu.co

***Politólogo, Magister en Filosofía Latinoamericana, Especialista en Edumática, Coordinador de Investigaciones de la Facultad de Derecho de la Universidad La Gran Colombia. E-mail: daniel.barragan@ugc.edu.co

Fecha de recepción: 15 julio de 2019

Fecha de aprobación: 30 de Noviembre de 2019

Para citar este artículo / To reference this article Ángel, L,K. Barragán, D, A. (2019) Evolución y desarrollo legislativo del cooperativismo en Colombia desde 1991. Inciso,

\section{Resumen}

DOI: http://dx.doi.org/10.18634/incj.21v.2i.987

El artículo tiene como objetivo principal, identificar el proceso legislativo del cooperativismo en Colombia, desde la promulgación de la Constitución de 1991 hasta el año 2016, describiendo fracciones de tiempo que abren un camino para el entendimiento de las actividades económicas y sociales legisladas sobre el cooperativismo en el país. El desarrollo del estudio y cumplimiento del objetivo general, está sujeto a una metodología netamente de enfoque cualitativo, que prevé el uso de una técnica de recolección de datos, en esta caso solo leyes, y su descripción. La clasificación de los datos, conlleva a la identificación de tres periodos temporales históricos de producción legislativa sobre cooperativismo; un primer periodo de 1991 a 2004, donde se marca un nuevo inicio del cooperativismo a partir del nacimiento de la Constitución colombiana de 1991 y su desarrollo; un segundo periodo de 2005 a 2016, todo lo anterior está dirigido a construir un artículo de revisión, que construirá las bases del desarrollo de toda la investigación a la cual pertenece en el presente estudio.

Palabras clave: Cooperativa, cooperación económica, economía, organización privada, Estado. 


\section{Abstract}

The main objective of this article is to identify the legislative process of cooperativism in Colombia, from the promulgation of the 1991 Constitution until 2016, describing fractions of time that open a path for the understanding of the economic and social activities legislated on cooperativism in the country. The development of the study and fulfillment of the general objective is subject to a methodology with a purely qualitative approach, which foresees the use of a data collection technique, in this case only laws, and their description.

The classification of the data leads to the identification of three historical temporary periods of legislative production on cooperativism; a first period from 1991 to 2004, which marks a new beginning of cooperativism from the birth of the Colombian Constitution of 1991 and its development; a second period from 2005 to 2016, all of the above is aimed at building an article of revision, which will build the basis for the development of all the research to which it belongs in this study.

Key words: Economic cooperation, collective economy, Private organization, industrial sector, Economy, Cooperative, State, Law.

\section{Introducción}

En consideración con el proyecto de investigación: "Cooperativismo. Ámbito de actuación para el desarrollo socioeconómico en Colombia”, que se desarrolla en el Centro de investigaciones de la Universidad La Gran Colombia desde noviembre de 2016, surgió una pregunta de investigación que enfatiza en la importancia del cooperativismo para la sociedad:

¿Cómo el cooperativismo en Colombia puede convertirse en un mecanismo eficaz para resolver algunos de sus graves problemas: emigración a las ciudades, envejecimiento y despoblamiento de las zonas rurales, pobreza estructural de las áreas más deprimidas, explotación de la mano de obra, falta de incorporación de valor añadido a los recursos disponibles de integración económico-social de los grupos armados tras la consecución de la paz?

De esta forma, en primera instancia, se pretende describir el proceso histórico que se presentó de 1991 a 2004, comprendiendo la evolución del cooperativismo como forma de solucionar problemas de índole económica y social al interior del país, que se preveía en las prácticas de empresa que se fundamentan en las relaciones comunitarias y familiares que surgen del ámbito cooperativo. A su vez, desarrollar la historia legislativa reciente entre el año 2005 a 2016, como fase de asentamiento y acoplamiento de la institución jurídica al nuevo mundo globalizado en el ordenamiento colombiano.

En particular, el objetivo a cumplir con el presente escrito se determina en recopilar los antecedentes exclusivamente legislativos existentes en Colombia desde 1991 y que han dado lugar a la situación actual del cooperativismo. Es así, que el documento retoma los principales procesos legislativos históricos, los acontecimientos y algunos de los protagonistas, además de la consagración de la economía cooperativa y solidaria en el escenario normativo.

La historia del cooperativismo en Colombia tiene diversas etapas, desde los primeros procesos de acercamiento y desarrollo hasta su consolidación. El presente texto tiene como propósito 
señalar los principales acontecimientos que han marcado la historia del cooperativismo en el país a partir del nacimiento de un Estado social de derecho, es decir, desde la entrada en vigencia de la Constitución colombiana de 1991 y determinar cómo ha evolucionado en diversos aspectos desde el punto de vista meramente legislativo, siendo fundamental el desarrollo del modelo económico y social para el progreso de la comunidad.

En este sentido, se examinarán los principales avances legislativos sobre el cooperativismo a través del estudio descriptivo de cada una de las leyes expedidas en un primer periodo de 1991 a 2004, denominado desarrollo legislativo del cooperativismo a finales del siglo XX, y el segundo periodo de 2005 - 2016 designado avances legislativos del cooperativismo en la actualidad.

\section{Materiales y metodos}

El artículo es realizado bajo los criterios de un enfoque cualitativo, utilizando técnicas de revisión bibliográfica, específica en la selección y clasificación de las leyes sobre cooperativismo en el periodo de 1991 al 2016. Específicamente se describen las leyes tendencialmente a identificar los aportes que cada norma ofrece al desarrollo del cooperativismo en Colombia.

\section{Desarrollo legislativo del cooperativismo en el periodo entre 1991-2004 en Colombia}

Entrando a la década de 1990 y con un mundo político cambiante y polarizado por la hegemonía de los Estados Unidos y sus empresas multinacionales, después de la caída del muro de Berlín y la finalización de la Guerra Fría, la situación económica y social de Colombia empezó a tornarse negativa debido a la alta competitividad de los productos que provenían del extranjero con nuevas modalidades de producción, haciendo un efecto dominó en la construcción que sobre el sector cooperativo se había desarrollado desde 1930 hasta ese momento (Pardo-Martínez y Huertas, 2014). Además, la implementación de un Estado neoliberal en Colombia y la desaparición del Estado de bienestar, la efectiva ayuda a la creación de nuevas cooperativas tendió a declinar, lo que a su vez produjo un des-escalamiento del progreso económico del sector cooperativo (Fisher, 1998) que se fue diluyendo en una crisis de recursos y de abandono de un Estado que se alejaba de la intervención social a causa del déficit fiscal y la crisis de la deuda que aún agobia al Estado colombiano (Uribe, 2004).

No obstante, el sector cooperativo siguió registrando una alta participación de la sociedad (Fuoquet, 1944), que intentó en medio de un debacle económico y político, adaptarse a la crisis y aprovechar lo expuesto en la nueva carta política de 1991 que proveyó en varios de sus artículos elementos para el mantenimiento del sector, como parte de la Economía Solidaria (Pardo, Serrano y Jaramillo, 2006).

Así, se presenta el desarrollo legislativo de 1991 a 2004:

La primera construcción legislativa se presentó con la Ley 9 de 1991 "Por la cual se dictan normas generales a las que deberá sujetarse el Gobierno Nacional para regular los cambios internacionales y se adoptan medidas complementarias", donde el sector del cooperativismo fue reglamentado, principalmente, para los caficultores, como se cita:

Artículo 26. Comité de precios internos del café. Los precios internos del café para las compras que realice la Federación Nacional de Cafeteros de Colombia con recursos del Fondo Nacional del Café se señalarán por un comité integrado por los Ministros de Hacienda y Crédito Público y de 
Agricultura y por el Gerente de la Federación Nacional de Cafeteros. Este mismo Comité adoptará medidas que faciliten la compra del café de los pequeños y medianos productores directamente por la Federación, o por las cooperativas de caficultores, con el objeto de que los precios que se fijen para tales operaciones los beneficien efectivamente. (Ley 9 de 1991, art.,26)

Como se puede observar, la ley reglamenta los comités de precios internos del café y afecta directamente a las cooperativas de caficultores, uno de los sectores económicos más representativos del ámbito colombiano, siendo parte del reconocimiento internacional que se tiene en la producción de Colombia.

Posteriormente, en el año de 1993 se presentó un desarrollo legislativo y normativo que determinaría los nuevos escenarios de las cooperativas a finales del siglo XX. Ejemplo de ello fueron: la Ley 101 de 1993: "Ley General de Desarrollo Agropecuario y Pesquero"; la Ley 35 de 1993: "Por la cual se dictan normas generales y se señalan en ellas los objetivos y criterios a los cuales debe sujetarse el Gobierno Nacional para regular las actividades financiera, bursátil y aseguradora y cualquier otra relacionada con el manejo, aprovechamiento e inversión de recursos captados del público y se dictan otras disposiciones en materia financiera y aseguradora"; la Ley 80 de 1993: "Por la cual se expide el Estatuto General de Contratación de la Administración Pública"; la Ley 100 de 1993: "Por la cual se crea el sistema de seguridad social integral y se dictan otras disposiciones"; la Ley 89 de 1993: "Por la cual se establece la Cuota de Fomento Ganadero y Lechero y se crea el Fondo Nacional del Ganado"; la Ley 82 de 1993: "Por la cual se expiden normas para apoyar de manera especial a la mujer cabeza de familia"; la Ley 105 de 1993: "Por la cual se dictan disposiciones básicas sobre el transporte, se redistribuyen competencias y recursos entre la Nación y las Entidades Territoriales, se reglamenta la planeación en el sector transporte y se dictan otras disposiciones"; la Ley 65 de 1993: "Por la cual se expide el Código Penitenciario y Carcelario"; la Ley 41 de 1993: "Por la cual se organiza el subsector de adecuación de tierras y se establecen sus funciones"; y la Ley 37 de 1993: "Por la cual se regula la prestación del servicio de telefonía móvil celular, la celebración de contratos de sociedad y de asociación en el ámbito de las telecomunicaciones y se dictan otras disposiciones".

De lo anterior, vale la pena destacar algunos artículos de la Ley 101 de 1993 que se relacionan con las cooperativas del sector agropecuario y pesquero:

Artículo 13. Operaciones a cargo del fondo para el financiamiento del sector agropecuario. Además de los fines estipulados en el artículo 26 de la Ley 16 de 1990, la Comisión Nacional de Crédito Agropecuario establecerá líneas de redescuento, dotadas del volumen suficiente de recursos y bajo condiciones financieras apropiadas, con el objeto de que los establecimientos de crédito puedan otorgar créditos en moneda nacional y extranjera para los siguientes fines:

.... 10. Organización y operación de cooperativas agrícolas y pesqueras (Ley 101 de 1993).

Artículo 27. Sin perjuicio de lo establecido en el artículo 28 de la Ley 16 de 1990, el Fondo Agropecuario de Garantías también podrá respaldar los créditos otorgados por las demás instituciones bancarias, financieras, fiduciarias y cooperativas, debidamente autorizadas por la Superintendencia Bancaria para otorgar créditos con destino al sector agropecuario. (Ley 101, de 1993, art., 13)

A su vez, se pueden revisar los artículos que se relacionan con la Ley 35 de 1993 con respecto al cooperativismo: 
Artículo 3o. Instrumentos de la intervención. <Incorporado en el Decreto 663 de 1993, EOSF, bajo el artículo 48> En desarrollo de lo previsto en el artículo 10., el Gobierno Nacional tendrá las siguientes funciones de intervención en relación con las entidades financieras y aseguradoras sujetas al control y vigilancia de la Superintendencia Bancaria y, en general, respecto de las entidades cuyas actividades consistan en el manejo, aprovechamiento y la inversión de recursos captados del público:

Parágrafo 3o. El Gobierno Nacional dictará las normas necesarias para la aplicación de las disposiciones que se expidan conforme a este artículo, tomando en cuenta la naturaleza específica de las instituciones financieras cooperativas. (Ley 35 de 1993, art., 3)

En este escenario, se puede hacer un análisis de la reglamentación que desarrolló el legislativo en cuanto al cooperativismo y la intervención al sector económico financiero.

En cuanto al análisis de la Ley 80 de 1993, vale la pena señalar la forma como está construido el Estatuto general de la administración pública en Colombia y cómo afecta al sector cooperativo:

Artículo $2^{\circ}$.- De la Definición de Entidades, Servidores y Servicios Públicos. Para los solos efectos de esta Ley:

Parágrafo. - Para los solos efectos de esta Ley, también se denominan entidades estatales las cooperativas y asociaciones conformadas por entidades territoriales, las cuales estarán sujetas a las disposiciones del presente estatuto, especialmente cuando en desarrollo de convenios interadministrativos celebren contratos por cuenta de dichas entidades. (Ley 80 de 1993, art., 2)

Concluyendo el análisis legislativo en materia de cooperativismo en el año de 1993, en cuanto a la Ley 37, se debe entender el desarrollo primario de las empresas de telefonía celular con respecto de lo cual se observa:

Artículo $12^{\circ}$.- Las empresas adjudicatarias de las concesiones de esta Ley, dentro de los cuatro años siguientes a la adjudicación de la concesión deberán acreditar el siguiente requisito, sin perjuicio de los demás que ordene las normas: Que por lo menos un 10\% de su capital deberá pertenecer al sector social solidario, que para los efectos de esta Ley se entiende integrado por las organizaciones sindicales, las funciones, corporaciones y asociaciones sin ánimo de lucro, los fondos de empleados, los fondos mutuos, o las instituciones cooperativas. (Ley 37 de 1993)

Lo anterior, evidencia la oportunidad que se creaba para el sector del cooperativismo, con la posibilidad de entrar en uno de los sectores productivos más importantes a nivel internacional, como lo es la telefonía móvil, que posibilita el desarrollo empresarial de las organizaciones sindicales, de empleados, mutuales y su participación activa en el 10\% del capital de las empresas concesionarias de las que se determinan en la Ley 37 de 1993.

Para el año 1994, se observa la redacción de las leyes: 115: "Por la cual se expide la Ley general de educación"; 142: "Por la cual se establece el régimen de los servicios públicos domiciliarios y se dictan otras disposiciones"; 118: "Por la cual se establece la cuota de fomento hortofrutícola, se crea un fondo de fomento, se establecen normas para su recaudo y administración y se dictan otras disposiciones"; 146: "Por medio de la cual se aprueba la "Convención Internacional sobre la Protección de los Derechos de todos los Trabajadores Migratorios y de sus Familiares", hecha en Nueva York el 18 de diciembre de 1990; 160: "Por la cual se crea el Sistema Nacional de Reforma Agraria y Desarrollo Rural Campesino, se establece un subsidio para la adquisición de tierras, se reforma el Instituto Colombiano de la Reforma Agraria y se dictan otras disposiciones"; 143: 
“Por la cual se establece el régimen para la generación, interconexión, trasmisión, distribución y comercialización de electricidad en el territorio nacional, se conceden unas autorizaciones y se dictan otras disposiciones en materia energética"; y 161: "Por la cual se organiza la Corporación Autónoma Regional del Río Grande de la Magdalena, se determinan sus fuentes de financiación y se dictan otras disposiciones".

En el año de 1994, una de las leyes más representativas fue la Ley 115 que para el escenario del cooperativismo tuvo presente las instituciones educativas en este nivel de organización, lo cual se observa en:

Artículo 3o. Prestación del servicio educativo. El servicio educativo será prestado en las instituciones educativas del Estado. Igualmente, los particulares podrán fundar establecimientos educativos en las condiciones que para su creación y gestión establezcan las normas pertinentes y la reglamentación del Gobierno Nacional. De la misma manera el servicio educativo podrá prestarse en instituciones educativas de carácter comunitario, solidario, cooperativo o sin ánimo de lucro. (Ley 115 de 1994, art.,3)

A la vez, se presenta como uno de los objetivos primordiales, enseñar dentro de la educación n básica, aportando a los colombianos los conocimientos necesarios para intervenir en el sector cooperativo, como se puede apreciar:

Artículo 20. Objetivos generales de la educación básica. Son objetivos generales de la educación básica:

d) Propiciar el conocimiento y comprensión de la realidad nacional para consolidar los valores propios de la nacionalidad colombiana tales como la solidaridad, la tolerancia, la democracia, la justicia, la convivencia social, la cooperación y la ayuda mutua (Ley 115 de 1994, art.,20)

En cuanto a la Ley 142 de 1994, se observa la forma cómo se legisla al sector cooperativo en un escenario tan fundamental como lo es la prestación de los servicios públicos:

Artículo 8o. Competencia de la Nación para la prestación de los servicios públicos. Es competencia de la Nación:

8.4. Apoyar financiera, técnica y administrativamente a las empresas de servicios públicos o a los municipios que hayan asumido la prestación directa, así como a las empresas organizadas con participación de la Nación o de los Departamentos para desarrollar las funciones de su competencia en materia de servicios públicos y a las empresas cuyo capital pertenezca mayoritariamente a una o varias cooperativas o empresas asociativas de naturaleza cooperativa. (Ley 142 de 1994, art.,8)

Aquí se observa la apertura que hace el legislativo al cooperativismo dentro del sector de la prestación de los servicios públicos, eje fundamental de la economía nacional, y que da una mayor prestancia a la economía desarrollada por las cooperativas, un escenario fundamental para el crecimiento económico de las comunidades desde los espacios locales y municipales, abriendo un abanico de posibilidades para la creación de nuevos escenarios de la economía en servicios.

Frente a la Ley 160 de 1994, se presenta un estudio en el cual es fundamental describir la forma como se realiza la política de tierras: 
Artículo 70. Las Unidades Agrícolas Familiares sobre tierras baldías se adjudicarán conjuntamente a los cónyuges o compañeros permanentes, siempre que hayan cumplido dieciséis años de edad, sean jefes de familia, compartan entre sí las responsabilidades sobre sus hijos menores, o con sus parientes hasta el segundo grado de consanguinidad si velaren por ellos.

Los adjudicatarios podrán contraer las obligaciones inherentes sin necesidad de autorización judicial. Esta disposición se aplicará a todas las adjudicaciones o adquisiciones de tierras que llegaren a hacerse en favor de los campesinos, o para la admisión de éstos como socios de las empresas comunitarias o cooperativas rurales. (Ley 160 de 1994, art. 70)

Las unidades agrícolas familiares sobre tierras baldías, su apropiación y aprovechamiento, van de la mano de la creación y fortalecimiento de las empresas comunitarias o cooperativas rurales, que hacen un constante aporte al desarrollo económico del campo colombiano y ofrece la posibilidad de establecer un camino a seguir, para muchos de los desposeídos que ha dejado el conflicto armado interno. Esto a su vez, se realiza en articulación con las corporaciones del Estado como Cormagdalena, reglamentado en la Ley 161 de 1994, así:

Artículo 6o. Funciones y facultades. La Corporación Autónoma Regional del Río Grande de la Magdalena, Cormagdalena, tendrá las siguientes funciones y facultades:

6. Promover, impulsar y asistir técnica y financieramente la formación y actividades de asociaciones, cooperativas y toda clase de agrupaciones comunitarias que persigan el desarrollo y la explotación adecuada de los recursos ictiológicos y agrícolas en el área de actividades de la Corporación, dentro de los parámetros de protección de los recursos naturales y del medio ambiente. (Ley 160 de 1994, art. 6)

En el año 1995, la producción legislativa en cuanto al cooperativismo determina una reducción sistemática, considerando los años anteriores, lo cual explica mucho del retroceso de muchos escenarios de la economía de las cooperativas en Colombia.

En principio, para 1995, las leyes a considerar fueron: Ley 188: "Plan Nacional de Desarrollo e Inversiones 1995 -1998"; Ley 223: "Por la cual se expiden normas sobre Racionalización Tributaria y se dictan otras disposiciones"; Ley 226: "Por la cual se desarrolla el artículo 60 de la Constitución Política en cuanto a la enajenación de la propiedad accionaria estatal, se toman medidas para su democratización y se dictan otras disposiciones"; y Ley 201: "Por la cual se establece la estructura y organización de la Procuraduría General de la Nación, y se dictan otras disposiciones".

Del Plan Nacional de Desarrollo e Inversiones 1995 - 1998, previsto en la Ley 188 de 1995, se observa la realización de una política pública que afecta determinantemente el escenario de las cooperativas:

Artículo 20. La descripción de los principales programas y subprogramas que el Gobierno Nacional espera ejecutar en la vigencia del Plan Nacional de Inversiones 1995 -1998 es la siguiente:

1. Social. 1.5. Empleo. 1.5.3. Economía solidaria.

Se apoyará la integración del sector a la ejecución de los programas prioritarios de política social y se impulsará la creación y el fortalecimiento de las organizaciones existentes, incluyendo las relacionadas con los sectores agropecuarios y agroindustrial. Las entidades territoriales promocionarán la puesta en marcha de las cooperativas juveniles productivas. (Ley 188 de 1995, art. 20) 
En cuanto a la Ley 223 de 1995, se observa a las cooperativas como contribuyentes del régimen tributario especial, lo que determina gran parte de su declive económico:

Artículo 63. Contribuyentes del Régimen Tributario Especial. El artículo 19 del Estatuto Tributario quedará así: "Artículo 19. Contribuyentes del Régimen Tributario Especial. Las entidades que se enumeran a continuación se someten al impuesto sobre la renta y complementarios, conforme al régimen tributario especial contemplado en el Título VI del presente Libro." 4. Las cooperativas, sus asociaciones, uniones, ligas centrales, organismos de grado superior de carácter financiero, las asociaciones mutualistas, instituciones auxiliares del cooperativismo y confederaciones cooperativas, previstas en la legislación cooperativa. El beneficio neto o excedente de estas entidades estará sujeto a impuesto cuando lo destinen; en todo o en parte, en forma diferente de lo que establece la legislación cooperativa vigente. "Parágrafo 3. En todo caso, las entidades cooperativas a las cuales se refiere el numeral 4 de este artículo no están sujetas a la retención en la fuente, sin perjuicio de las obligaciones que les correspondan como agentes retenedores, cuando el Gobierno Nacional así lo disponga". (Ley 223, 1995, art. 63)

Lo anterior, determina un escenario regresivo en la economía de las cooperativas, considerando que al gravarse impuestos en este sector, se observa un escenario cada vez más proclive a obstaculizar el desarrollo de las empresas comunitarias, haciendo que gran parte de la producción se desincentive, observando la naturaleza de estas organizaciones, su difícil inicio y su mantenimiento en el mercado nacional.

De acuerdo con la Ley 226 de 1995 se presenta un análisis de la forma como se desarrolla el artículo 60 constitucional, en cuanto a la enajenación de la propiedad accionaria estatal, se toman medidas para su democratización y se dictan otras disposiciones:

Artículo $3^{\circ}$.- Preferencia. Para garantizar el acceso efectivo a la propiedad del Estado, se otorgarán condiciones especiales a los sectores indicados en el siguiente inciso, encaminadas a facilitar la adquisición de la participación social estatal ofrecida, de acuerdo el artículo 60 constitucional.

Serán destinatarios exclusivos de las condiciones especiales: los trabajadores activos y pensionados de la entidad objeto de privatización y de las entidades donde esta última tenga participación mayoritaria; los ex trabajadores de la entidad objeto de privatización y de las entidades donde esta última tenga participación mayoritaria siempre y cuando no hayan sido desvinculados con justa causa por parte del patrono; las asociaciones de empleados o ex empleados de la entidad que se privatiza, sindicatos de trabajadores; federaciones de sindicatos de trabajadores y confederaciones de sindicatos de trabajadores; los fondos de empleados; los fondos mutuos de inversión; los fondos de cesantías y de pensiones; y las entidades cooperativas definidas, por la legislación cooperativa. (Ley 226 de 1995, art.3)

En principio, esta ley determina la esencia de la privatización de las entidades del Estado y de economía mixta como las cooperativas, vulnerando mucho de lo desarrollado en este ámbito en años anteriores y generando un desbalance de las ganancias de los trabajadores frente al crecimiento del sector privado nacional y sobre todo internacional, con respecto al mercado accionario del Estado colombiano.

Para el año 1996, la legislación fue muy limitada en materia de cooperativismo, teniendo presente solamente la redacción de dos leyes, como lo fueron: la Ley 272: "Por la cual se crea la cuota de fomento porcino y se dictan normas sobre su recaudo y administración"; y la Ley 262: "Por la cual se autoriza a algunas cooperativas financieras para acceder a los recursos del 
Fondo para el Financiamiento del Sector Agropecuario -Finagro- y se dictan normas generales, objetivos y criterios a los cuales debe sujetarse el Gobierno Nacional para la intervención de estas entidades".

En cuanto a esta última, la Ley 262 de 1996, se puede observar su incidencia en el sector financiero como se aprecia:

Artículo 10. Las cooperativas especializadas de ahorro y crédito y las cooperativas multiactivas con sección de ahorro y crédito, debidamente autorizadas por el Departamento Administrativo Nacional de Cooperativas y que ejerzan la actividad financiera con terceros, podrán redescontar ante el Fondo para el Financiamiento del Sector Agropecuario -FINAGRO- los créditos agropecuarios que otorguen, de acuerdo con los términos y condiciones que señale la Comisión Nacional de Crédito Agropecuario. (Ley 262 de 1996, art. 1)

De lo anterior, se puede apreciar la baja atención que el Estado prestó al sector cooperativo para este año, considerando los escenarios de privatización de las empresas comunitarias iniciadas desde 1995 y acelerando una drástica caída de todo el sector económico cooperativo, que hasta nuestros días no ha podido recuperarse.

En el escenario de 1997, se identifican las leyes: 383: "Por la cual se expiden normas tendientes a fortalecer la lucha contra la evasión y el contrabando, y se dictan otras disposiciones"; 395: "Por la cual se declara de interés social nacional y como prioridad sanitaria la erradicación de la fiebre aftosa en todo el territorio colombiano y se dictan otras medidas encaminadas a este fin"; 347: "Por medio de la cual se aprueban las Recomendaciones 171 sobre los servicios de Salud en el Trabajo; 172 sobre la utilización del asbesto en condiciones de seguridad; 173 sobre el bienestar de la gente de mar en el mar y en puerto; 174 sobre la repatriación de la gente de mar; 176 sobre el fomento del empleo y la protección contra el desempleo; 178 sobre el trabajo nocturno; 179 sobre las condiciones de trabajo en los hoteles, restaurantes y establecimientos similares y 180 sobre la protección de los créditos laborales en caso de insolvencia del empleador, adoptadas por la Conferencia General de la Organización Internacional del Trabajo"; 363: "Por medio de la cual se reforma la Ley número 132 de 1994, estatuto orgánico de los fondos ganaderos"; 365: "Por la cual se establecen normas tendientes a combatir la delincuencia organizada y se dictan otras disposiciones"; 378: "Por medio de la cual se aprueba el "Convenio número 161, sobre los servicios de salud en el trabajo" adoptado por la 71 Reunión de la Conferencia General de la Organización Internacional del Trabajo, OIT, Ginebra, 1985"; y la Ley 375: "Por la cual se crea la Ley de la juventud y se dictan otras disposiciones".

De este año, se colige un escenario de fortalecimiento institucional contra la evasión y el contrabando, fenómenos que afectan directamente la acumulación del capital en el sector productivo, sin embargo, se aprecia una constante reducción de la normatividad con respecto al cooperativismo.

Para 1998, se generaron las leyes: 454: "Por la cual se determina el marco conceptual que regula la economía solidaria, se transforma el Departamento Administrativo Nacional de Cooperativas en el Departamento Nacional de la Economía Solidaria, se crea la Superintendencia de la Economía Solidaria, se crea el Fondo de Garantías para las Cooperativas Financieras y de Ahorro y Crédito, se dictan normas sobre la actividad financiera de las entidades de naturaleza cooperativa y se expiden otras disposiciones"; 436: "Por medio de la cual se aprueba el Convenio 162 sobre Utilización del Asbesto en Condiciones de Seguridad”, adoptado en la 72a. Reunión de la Conferencia General de la Organización Internacional del Trabajo, Ginebra 1986". 
En el año 1998, se evidencia un desarrollo particular de las cooperativas hacia el sector solidario, y se crea una reglamentación para las entidades de naturaleza financiera.

En el año de 1999, se emiten las leyes: 510: "Por la cual se dictan disposiciones en relación con el sistema financiero y asegurador, el mercado público de valores, las Superintendencias Bancaria y de Valores y se conceden unas facultades"; 534: "Por la cual se establece la Cuota de Fomento para la Modernización y Diversificación del Subsector Tabacalero y se dictan otras disposiciones"; 550: "Por la cual se establece un régimen que promueva y facilite la reactivación empresarial y la reestructuración de los entes territoriales para asegurar la función social de las empresas y lograr el desarrollo armónico de las regiones y se dictan disposiciones para armonizar el régimen legal vigente con las normas de esta Ley"; 547: "Por la cual se decreta el Presupuesto de Rentas y Recursos de Capital y Ley de Apropiaciones para la Vigencia Fiscal del 10. de enero al 31 de diciembre del 2000"; 546: "Por la cual se dictan normas en materia de vivienda, se señalan los objetivos y criterios generales a los cuales debe sujetarse el Gobierno Nacional para regular un sistema especializado para su financiación, se crean instrumentos de ahorro destinado a dicha financiación, se dictan medidas relacionadas con los impuestos y otros costos vinculados a la construcción y negociación de vivienda y se expiden otras disposiciones"; 508: "Por la cual se expide el Plan Nacional de Desarrollo para los años de 1999-2002"; y la Ley 517: "Por medio de la cual se aprueba el "Acuerdo de cooperación para la prevención, control y represión del lavado de activos derivado de cualquier actividad ilícita entre el Gobierno de la República de Colombia y el Gobierno de la República del Paraguay", hecho en Santa Fe de Bogotá, D. C., el treinta y uno (31) de julio de mil novecientos noventa y siete (1997)".

En el año 2000, se realizaron las leyes: 633: "Por la cual se expiden normas en materia tributaria, se dictan disposiciones sobre el tratamiento a los fondos obligatorios para la vivienda de interés social y se introducen normas para fortalecer las finanzas de la Rama Judicial"; 617: "Por la cual se reforma parcialmente la Ley 136 de 1994, el Decreto Extraordinario 1222 de 1986, se adiciona la Ley Orgánica de Presupuesto, el Decreto 1421 de 1993, se dictan otras normas tendientes a fortalecer la descentralización, y se dictan normas para la racionalización del gasto público nacional"; y la Ley 628: "Por la cual se decreta el Presupuesto de Rentas y Recursos de Capital y Ley de Apropiaciones para la vigencia fiscal del 10. de enero al 31 de diciembre de 2001".

Frente al año 2001, se producen las leyes: 685: "Por la cual se expide el Código de Minas y se dictan otras disposiciones"; 726: "Por medio de la cual se modifican algunos artículos de la Ley 118 de 1994"; 714: "Por la cual se decreta el Presupuesto de Rentas y Recursos de Capital y Ley de Apropiaciones para la vigencia fiscal del 10. de enero al 31 de diciembre de 2002"; y 674: "Por medio de la cual se aprueba el "Acuerdo de Cooperación para la prevención, control y represión del Lavado de Activos derivados de cualquier actividad ilícita entre el Gobierno de la República de Colombia y el Gobierno de la República Dominicana”, hecho en Santo Domingo, el 27 de junio de 1998".

En el escenario del año 2002, se desarrolló la Ley 789: "Por la cual se dictan normas para apoyar el empleo y ampliar la protección social y se modifican algunos Artículos del Código Sustantivo de Trabajo".

Para el año 2003, se crean las leyes: 863: "Por la cual se establecen normas tributarias, aduaneras, fiscales y de control para estimular el crecimiento económico y el saneamiento de las finanzas públicas"; 811: "Por medio de la cual se modifica la Ley 101 de 1993, se crean las organizaciones de cadenas en el sector agropecuario, pesquero, forestal, acuícola, las 
Sociedades Agrarias de Transformación, SAT, y se dictan otras disposiciones"; y la Ley 825: "Por medio de la cual se aprueba el Convenio-Marco relativo a la ejecución de la Ayuda Financiera y Técnica y de la Cooperación Económica en la República de Colombia en virtud del Reglamento "ALA", firmado en Bruselas el diecisiete (17) de octubre de dos mil (2000) y en Bogotá, el catorce (14) de diciembre de dos mil (2000)".

Finalmente, en el año 2004 se observaron las leyes: 920: "Por la cual se autoriza a las cajas de compensación familiar adelantar actividad financiera y se dictan otras disposiciones"; 915: "Por la cual se dicta el Estatuto Fronterizo para el Desarrollo Económico y Social del departamento Archipiélago de San Andrés, Providencia y Santa Catalina"; 921: "Por la cual se decreta el Presupuesto de rentas y recursos de capital y Ley de apropiaciones para la vigencia fiscal del 10 de enero al 31 de diciembre de 2005".

\section{Avances legislativos del cooperativismo en la actualidad (2005 - 2016)}

En el año 2005 se vislumbraba un Estado que sembraba semillas en la construcción de grandes cambios, entre muchos se destacan la consolidación de la reelección presidencial, que daría lugar al segundo mandato de Álvaro Uribe Vélez; negociaciones finales para el TLC con Estados Unidos, y muchas negociaciones de capital externo, que marcan una nueva posición de Colombia frente al mundo; en materia de paz se reconoce como un año donde se fortaleció el acuerdo de paz con las AUC y muestra sus primeros resultados; bajo este panorama político y económico, desde el punto de vista legislativo, se avanzaba en el desarrollo del sector cooperativo, en los siguientes términos:

Para el 2005 el Congreso emite la Ley 952: “Por medio de la cual se modifica el artículo $2^{\circ}$ de la Ley 700 de 2001 y se dictan otras disposiciones", esta norma tiene como objetivo crear la obligación, para todos los operadores públicos y privados del sistema general de pensiones, que tengan a su cargo el giro y pago de las mesadas pensionales, de consignar la mesada correspondiente a cada pensionado en cuentas individuales, en la entidad financiera que el beneficiario elija, esto incluye dentro de las entidades financieras que puede escoger el pensionado, las cooperativas de Ahorro y Crédito o las Multiactivas integrales con secciones de ahorro y crédito vigiladas por la Superintendencia de la Economía Solidaria.

En el 2006 el cooperativismo se integra a la educación, se crea la Ley 1013 de 2006: "Por la cual se modifica el artículo 14 de la Ley 115 de 1994, el art.2, modifica el literal d) del artículo 14, establece la educación para la Justicia, la Paz, la Democracia, la Solidaridad, la Confraternidad, la Urbanidad, el Cooperativismo y en general la formación de los valores humanos". La Ley 1029 de 2006 "Por la cual se modifica el artículo 14 de la Ley 115 de 1994, tipificando la enseñanza obligatoria, y dicta:

En todos los establecimientos oficiales o privados que ofrezcan educación formal es obligatoria en los niveles de la educación preescolar, básica y media cumplir con:

d) La educación para la justicia, la paz, la democracia, la solidaridad, la confraternidad, el cooperativismo y, en general, la formación de los valores humanos. (Ley 1029, 2006, art. 14)

Para este mismo año se dictan normas en materia tributaria que favorecen las cooperativas de trabajo asociado y las precooperativas, la Ley 1111 de 2006, "Por la cual se modifica el Estatuto Tributario de los impuestos administrados por la Dirección de Impuestos y Aduanas Nacionales, obligando a adicionar al Estatuto el artículo 462-1, el cual dispone: 
Servicios gravados a la tarifa del 1.6\%. En los servicios de aseo, en los de vigilancia autorizados por la Superintendencia de Vigilancia Privada, en los de empleo temporal prestados por empresas autorizadas por el Ministerio de la Protección Social y en los prestados por las cooperativas y precooperativas de trabajo asociado en cuanto a mano de obra se refiere, vigiladas por la Superintendencia de Economía Solidaria o quien haga sus veces, a las cuales se les haya expedido resolución de registro por parte del Ministerio de la Protección Social, de los regímenes de trabajo asociado, compensaciones y seguridad social, la tarifa será del 1.6\%. (Negrilla fuera del texto, Ley 1111 de 2006, art. 462-1)

Además, exige que para la obtención de este beneficio el contribuyente debe cumplir con las obligaciones que surgen de la relación laboral o compensaciones en la relación laboral relativo a las cooperativas, incluidas las obligaciones de seguridad social, de este modo se protege también los derechos laborales a los asociados a este tipo de cooperativas.

También se adicionó al artículo 879 un parágrafo y un numeral, reglamentando las cooperativas financieras de ahorro y crédito así:

1. Los retiros efectuados de las cuentas de ahorro abiertas en entidades financieras $y / 0$ cooperativas de naturaleza financiera o de ahorro y crédito vigiladas por las Superintendencias Financiera o de Economía Solidaria respectivamente, que no excedan mensualmente de trescientas cincuenta (350) UVT, para lo cual el titular de la cuenta deberá indicar por escrito ante el respectivo establecimiento de crédito o cooperativa financiera, que dicha cuenta será la única beneficiada con la exención.

11. Los desembolsos de crédito mediante abono a la cuenta o mediante expedición de cheques que realicen los establecimientos de crédito, las cooperativas con actividad financiera o las cooperativas de ahorro y crédito vigiladas por las Superintendencias Financiera o de Economía Solidaria respectivamente.

14. Los traslados que se realicen entre cuentas corrientes y/o de ahorros abiertos en un mismo establecimiento de crédito, cooperativa con actividad financiera o cooperativa de ahorro y crédito vigiladas por las Superintendencias Financiera o de Economía Solidaria respectivamente a nombre de un mismo y único titular. (Ley 1111, 2006, art. 879)

Otra norma que impuso cambios en el régimen del cooperativismo, en el que se dispone someter a todas las cooperativas que realicen actividades de ahorro y crédito, bajo el régimen del Estatuto orgánico del sistema financiero es la Ley 1121 de 2006: "Por la cual se dictan normas para la prevención, detección, investigación y sanción de la financiación del terrorismo y otras disposiciones"; en el artículo 9 se modifica el artículo 23 de la Ley 365 de 1997, el cual quedará así:

Artículo 23. Entidades cooperativas que realizan actividades de ahorro y crédito. Además de las entidades Cooperativas de grado superior que se encuentren bajo la vigilancia de la Superintendencia Financiera o quien haga sus veces, también estarán sujetas a lo establecido en los artículos 102 a 107 del Estatuto Orgánico del Sistema Financiero, todas las entidades cooperativas que realicen actividades de ahorro y crédito. (Ley 1121, 2006, art. 23)

Para las cooperativas de ahorro y crédito y las multiactivas e integrales con sección de ahorro y crédito vigiladas por la Superintendencia de la Economía Solidaria, este ente de supervisión reglamentará lo dispuesto en los citados artículos del Estatuto Financiero y podrá modificar las cuantías a partir de las cuales deberá dejarse constancia de la información relativa a transacciones en efectivo. 
Las cooperativas de ahorro y crédito y las multiactivas e integrales con sección de ahorro y crédito, deberán informar a la UIAF la totalidad de las transacciones en efectivo de que trata el artículo 103 del Estatuto Orgánico del Sistema Financiero, conforme a las instrucciones que para el efecto imparta la Superintendencia de la Economía Solidaria.

Por su parte, en el año 2007 se expide la Ley 1150 de 2007 por medio de la cual se introducen medidas para la eficiencia y la transparencia en la Ley 80 de 1993 y se dictan otras disposiciones generales sobre la contratación con recursos públicos. En esta norma se incluyen las cooperativas y entes solidarios de carácter público, en el régimen de contratación pública y dicta las siguientes disposiciones:

Artículo 10. Tratamiento para las cooperativas y asociaciones de entidades territoriales. Las cooperativas, las asociaciones conformadas por entidades territoriales y en general los entes solidarios de carácter público estarán sometidos a las disposiciones del Estatuto General de Contratación de la Administración Pública. La celebración de contratos de entidades estatales con asociaciones o cooperativas de entidades territoriales y en general con entes solidarios, se someterá a los procesos de selección de que trata la presente Ley, en los que participarán en igualdad de condiciones con los particulares. (Ley 1150, 2007, art. 10)

Además, en materia de seguridad social en salud, el Congreso de la República regula con el objetivo de fortalecer el sistema de salud nacional, la creación de cooperativas, con la Ley 1127 de 2007, "Por la cual se hacen algunas modificaciones en el Sistema General de Seguridad Social en Salud y se dictan otras disposiciones", en el artículo 30 sobre el fortalecimiento de Asociaciones y/o Cooperativas de las ESE, establece:

El Gobierno Nacional, departamental y municipal promoverán la creación y el fortalecimiento de asociaciones y/o cooperativas de las ESEs, que tengan como objetivo fortalecer la red pública hospitalaria. Estas asociaciones y/o cooperativas ofrecerán servicios y/o podrán proveer insumos, siempre y cuando beneficien a las entidades con economía de escala, calidad, oportunidad, eficiencia y transparencia. (Ley 1127, 2007, art. 30)

También, el año 2008 fue muy importante para el cooperativismo, en este se dictaron un número importante de leyes que dieron lugar a su desarrollo.

Ley 1190 de 2008, "Por medio de la cual el Congreso de Colombia declara el 2008 como el año de la promoción de los derechos de las personas desplazadas por la violencia y se dictan otras disposiciones". Frente a las cooperativas otorga oportunidades a las conformadas por desplazados, para que presenten proyectos al gobierno para mejorar la calidad de vida, el artículo 6 dispone: En los proyectos presentados al Gobierno Nacional por las familias, asociaciones, cooperativas de desplazados, entes territoriales y organismos internacionales, donde se busca el mejoramiento de la calidad de vida de los desplazados, sobre los siguientes temas:

1. Proyectos de vivienda de interés social urbana y rural.

2. Adjudicación de tierras.

3. Proyectos productivos agropecuarios.

4. Proyectos de mejoramiento de calidad y cobertura de la educación.

5. Proyectos de atención en salud. 


\section{Cobertura de servicios públicos.}

\section{Ampliación de programas sociales.}

El Gobierno Nacional reglamentará en cada caso, para la viabilización y asignación de recursos de estos proyectos, dándoles prioridad en sus sistemas de calificación y aprobación.

No solo en tema de desplazados participa el sector cooperativo y de economía solidaria, sino también en la protección de la mujer cabeza de familia, por tal razón, se realizó una modificación a la Ley 82 de 1993, Ley Mujer Cabeza de Familia, a través de la Ley 1232 de 2008, que en el artículo 13 establece: El artículo 20 de la Ley 82 de 1993 quedará así:

Artículo 20. Garantías para el desarrollo sostenible. Para garantizar el desarrollo sostenible de los proyectos sociales que se promueven por la presente Ley a favor de las Mujeres Cabeza de Familia, se disponen las siguientes acciones:

a) El Departamento Administrativo Nacional de la Economía Solidaria, Dansocial, o quien haga sus veces, dirigirá, coordinará, promoverá, planeará, protegerá, fortalecerá y desarrollará proyectos de enfoque empresarial dirigidos a las mujeres cabeza de familia, mediante la ejecución de recursos provenientes del presupuesto nacional, de los particulares u originados en el extranjero, para promover la constitución de organizaciones de economía solidaria sin que esto avale las cooperativas de trabajo asociado que tercerizan las relaciones laborales; (negrilla fuera del texto, Ley 1232, 2008, art. 20)

Así mismo, en materia de género se emitió la Ley 1257 de 2008, "Por la cual se dictan normas de sensibilización, prevención y sanción de formas de violencia y discriminación contra las mujeres, se reforman los Códigos Penal, de Procedimiento Penal, la Ley 294 de 1996 y se dictan otras disposiciones", específicamente en tema de cooperativas de trabajo asociado, el artículo 12 sobre medidas en el ámbito laboral, determina que el Ministerio de la Protección Social, además de las señaladas en otras leyes, tendrá las siguientes funciones:

1. Promoverá el reconocimiento social y económico del trabajo de las mujeres e implementará mecanismos para hacer efectivo el derecho a la igualdad salarial.

2. Desarrollará campañas para erradicar todo acto de discriminación y violencia contra las mujeres en el ámbito laboral.

3. Promoverá el ingreso de las mujeres a espacios productivos no tradicionales para las mujeres.

Parágrafo. Las Administradoras de Riesgos Profesionales (ARP) los empleadores y o contratantes, en lo concerniente a cada uno de ellos, adoptarán procedimientos adecuados y efectivos para:

1. Hacer efectivo el derecho a la igualdad salarial de las mujeres.

2. Tramitar las quejas de acoso sexual y de otras formas de violencia contra la mujer contempladas en esta Ley. Estas normas se aplicarán también a las cooperativas de trabajo asociado y a las demás organizaciones que tengan un objeto similar.

3. El Ministerio de la Protección Social velará porque las Administradoras de Riesgos Profesionales (ARP) y las Juntas Directivas de las Empresas den cumplimiento a lo dispuesto en este parágrafo. (Ley 1257,2008 , art.12) 
Todavía cabe señalar la Ley 1233 de 2008: "Por medio de la cual se precisan los elementos estructurales de las contribuciones a la seguridad social, se crean las contribuciones especiales a cargo de las Cooperativas y Precooperativas de Trabajo Asociado, con destino al Servicio Nacional de Aprendizaje, Sena, al Instituto Colombiano de Bienestar Familiar, ICBF, y a las Cajas de Compensación Familiar, se fortalece el control concurrente y se dictan otras disposiciones". De tal manera, que las cooperativas y precooperativas de trabajo asociado, entran en las contribuciones especiales, que es la actividad de trabajo que desempeñan los asociados, a cargo de las cooperativas y precooperativas de trabajo asociado y con destino al Servicio Nacional de Aprendizaje, Sena, al Instituto Colombiano de Bienestar Familiar, ICBF, y a las cajas de compensación familiar. Por mandato de la ley, las cooperativas y precooperativas de trabajo asociado tendrán un representante en la Junta Directiva del Sena y un representante en la Junta Directiva del ICBF, quienes serán designados por las confederaciones nacionales que se las agremien. Estos recursos estarán bajo el control del gobierno nacional a través de la Superintendencia de la Economía Solidaria (Ley 1233, 2008).

En el artículo 6 se estipula que las cooperativas y precooperativas de trabajo asociado deben cumplir con afiliación al sistema de seguridad social, que estará a cargo de las afiliaciones y de los aportes de los trabajadores asociados al sistema de seguridad social integral, se le aplicarán las mismas disposiciones que a los dependientes. La norma también impone que unas prohibiciones a la actividad de las cooperativas y precooperativas de trabajo asociado, en el artículo 7 de la misma ley, por ejemplo: "No podrán actuar como empresas de intermediación laboral, ni disponer del trabajo de los asociados para suministrar mano de obra temporal a terceros o remitirlos como trabajadores en misión", además, tampoco podrán: “Actuar como asociaciones o agremiaciones para la afiliación colectiva de trabajadores independientes al Sistema de Seguridad Social ni como asociaciones mutuales para los mismos efectos" (Ley 1233, 2008). Por su parte el artículo 8 expresa que el régimen de trabajo asociado cooperativo colombiano estará alineado a los postulados, principios y directrices de la OIT, en relación con el trabajo digno y decente, además, seguirá los principios y valores universales proclamados por la Alianza Cooperativa Internacional. Ahora bien, sobre el objeto social de estas cooperativas la norma exige en el artículo 12 que estas organizaciones solidarias deben:

Generar y mantener trabajo para los asociados de manera autogestionaria, con autonomía, autodeterminación y autogobierno. En sus estatutos se deberá precisar la actividad económica que desarrollarán encaminada al cumplimiento de su naturaleza en cuanto a la generación de un trabajo, en los términos que determinan los organismos nacionales e internacionales sobre la materia. (Ley 1233, 2008, art. 12)

Finalmente, otro de los artículos de resaltar de esta ley es el 11, que exige que todo trabajador que sea asociado debe formarse en cooperativismo y economía solidaria, a través de un curso de mínimo de 20 horas, por una entidad certificada por Dansocial.

A su vez, el año 2009 aporta 3 nuevas leyes que integran el régimen cooperativo colombiano, a saber, la Ley 1357 de 2009: "Por la cual se modifica el Código Penal, que establece como delito la omisión de control, en la administración de cooperativas del sector financiero" (artículo 325); la Ley 1346 de 2009: "Por medio de la cual se aprueba la "Convención sobre los Derechos de las personas con Discapacidad", adoptada por la Asamblea General de la Naciones Unidas el 13 de diciembre de 2006, que en el artículo 27 sobre trabajo y empleo para las personas con discapacidad, se promueve la constitución de cooperativas como iniciativa empresarial; la Ley 1328 de 2009: "Por la cual se dictan normas en materia financiera, de seguros, del mercado de valores y otras disposiciones", en esta se regulan las cooperativas de ahorro y crédito, en la prestación de servicios y de inversión de capital. 
Con respecto al año 2010, se crean 2 leyes, la primera, la Ley 1429 de 2010: "Por la cual se expide la Ley de Formalización y Generación de Empleo", establece descuentos tributarios para los empleadores que realicen contrataciones de jóvenes, de personas de bajos ingresos y en condición de desplazamiento, en los artículos 9,10,11 y 13, los cuales expresan que estos beneficios no son aplicables a las cooperativas de trabajo asociado; la segunda en cambio, la Ley 1430 de 2010: "Por medio de la cual se dictan normas tributarias de control y para la competitividad", en esta se establecen normas que incluyen las cooperativas del sector financiero, en relación con los desembolsos de créditos, retiros y créditos obtenidos en el exterior, en los artículos 6, 35, 36 y 43.

Ahora bien, en el 2011 la legislación incorporó leyes que impactaron al régimen cooperativo, como la Ley 1438 de 2011: "Por medio de la cual se reforma el Sistema General de Seguridad Social en Salud y se dictan otras disposiciones". Declarada exequible por la Corte Constitucional mediante sentencia C-791 de 2011, en relación con las cooperativas, el artículo 76 sobre la eficiencia y transparencia en contratación, adquisiciones y compras de las Empresas Sociales del Estado y el artículo 103 sobre contratación del personal misional permanente. También la Ley 1474 de 2011: "Por la cual se dictan normas orientadas a fortalecer los mecanismos de prevención, investigación y sanción de actos de corrupción y la efectividad del control de la gestión pública", en el artículo 11 sobre el control y vigilancia en el sector de la seguridad social en salud, las cooperativas que prestan servicios de salud, no pueden hacer donaciones a campañas políticas o a actividades que no tengan relación con los servicios de salud.

Siguiendo el recorrido legislativo de este periodo se llega al 2012, donde se expiden la Ley 1607 de 2012: "Por la cual se expiden normas en materia tributaria y se dictan otras disposiciones", dispone una base gravable especial para las cooperativas y precooperativas de trabajo asociado, artículo 462-1; además, la Ley 1527 de 2012: "Por medio de la cual se establece un marco general para la libranza o descuento directo y se dictan otras disposiciones", sobre las cooperativas, se permite que los asociados puedan adquirir bienes y servicios, acreditados con sus salarios, pagos u honorarios (Ley 1527, 2012, art. 1), sobre el objeto de la libranza y descuentos directos; por último la Ley 1562 de 2012: "Por la cual se modifica el Sistema de Riesgos Laborales y se dictan otras disposiciones en materia de Salud Ocupacional", es de suma importancia, frente a los trabajadores asociados de cooperativas en cuanto, de forma obligatoria exige que las cooperativas y precooperativas de trabajo asociado, son las responsables conforme a la Ley, del proceso de afiliación y pago de los aportes de estos trabajadores al sistema general de riesgos laborales (Ley 1527, 2012, art. 13).

Pasando al 2014, la Ley 1739 de 2014: "Por medio de la cual se modifica el Estatuto Tributario, la Ley 1607 de 2012, se crean mecanismos de lucha contra la evasión y se dictan otras disposiciones"; sobre las cooperativas financieras, y las de ahorro y crédito, en el artículo 47, precisa reglas frente a las cuentas y productos que deben respetar estas entidades. Seguidamente, el año 2015 impone nuevas directrices para el cooperativismo colombiano, debido a la emisión del Plan de Nacional de Desarrollo 2014-2018, bajo la Ley 1753 de 2015, con el lema Todos por un nuevo país, el artículo 220, sobre promoción y fomento de las empresas minipymes cooperativas y de la economía solidaria, reconoce a estas empresas con el mismo tratamiento de las demás tipos de empresas, ya sean estas empresas cooperativas, o de economía solidaria, este tratamiento en condiciones de igualdad frente a las entidades estatales, legitima la creación y fomento de este tipo de cooperativas. En este mismo año se expide la Ley 1755 de 2015: "Por medio de la cual se regula el Derecho Fundamental de Petición y se sustituye un título del Código de Procedimiento Administrativo y de lo Contencioso Administrativo", en esta norma se regula como 
fundamental el derecho de petición presentado ante entidades privadas, como las cooperativas, las cuales deben acatar la norma y responder de acuerdo con la misma, esta regulación se encuentra en el artículo 32.

Para finalizar el camino por esta etapa del desarrollo normativo actual del cooperativismo, se cierra con una norma del 2016, la Ley 1780: "Por medio de la cual se promueve el empleo y el emprendimiento juvenil, se generan medidas para superar barreras de acceso al mercado de trabajo y se dictan otras disposiciones", la cual en el artículo 27, sobre educación económica y financiera, cooperativa y solidaria en el sistema educativo, establece:

Para avanzar en el propósito nacional de que la niñez y la juventud reciban educación económica y financiera, en todas las instituciones educativas, públicas y privadas, se impulsará en todos los ciclos educativos, la cultura de la solidaridad, y la cooperación, así como el desarrollo del modelo empresarial cooperativo y de la economía solidaria, como alternativa de asociatividad y emprendimiento cooperativo y solidario para la generación de ingresos, y la adecuada valoración de la economía. Parágrafo. Se apoyarán las experiencias de cooperativas escolares, como forma de emprendimiento cooperativo y como apoyo al proceso educativo en las áreas curriculares. (Ley 1780,2016 , art. 27)

\section{Conclusiones}

El cooperativismo en Colombia desde la vigencia de la carta constitucional de 1991 se describe a través de un recorrido por las leyes emanadas en dos periodos históricos de 1991 a 2004 y de 2005 a 2016, considerando que de acuerdo con la política neoliberal de la década de 1990, el sector tendió a desregularse y se convirtió en un escenario mayoritariamente privado, donde el sector financiero obtendrá una privilegiada posición frente a los demás sectores de la economía tradicional, como lo era en décadas pasadas la agricultura, que perderá a una de sus más importantes instituciones como lo era Idema (Instituto de Mercadeo Agropecuario) en 1996, generándose un escenario proclive para la inversión extranjera directa y la falta de apoyo al sector agropecuario por parte del Estado, siendo una tendencia que pervive hasta nuestro tiempo (Benecke y Boettcher, 1992).

En materia de legislación se robusteció el sector financiero para su regulación y consolidación en la década de 1990, sin embargo, la banca ha centralizado el funcionamiento del sector, haciendo que cada vez más el sector cooperativo se distancie de los principales escenarios de este sector económico.

Actualmente, el cooperativismo es un sector de la economía que se reúne a su vez en gremios de la economía, como se observa en el sector ganadero, lechero, arrocero y en sectores de la economía de servicios como la educación, siendo una importante fuente de desarrollo económico en el país.

Vale la pena afirmar que el cooperativismo se desarrolla como un sector primario para el emprendimiento y la innovación, considerando que asociaciones de trabajadores, estudiantes y la comunidad en general pueden realizar proyectos de empresas PYME, que con el apoyo del Estado surgen como la forma de establecer nuevos escenarios económicos para un país en vías de desarrollo.

A grandes rasgos, el primer periodo de 1991 a 2004 podría entenderse como un tiempo de reestructuración del cooperativismo en Colombia, de acuerdo con la legislación desarrollada, haciendo que mayoritariamente el sector privado obtuviera una posición privilegiada, mientras 
que en el segundo periodo de 2005 a 2016, se destaca el desarrollo normativo en relación con promover la constitución de cooperativas y el control para la eficiencia de las cooperativas del sector financiero, ahorro y crédito. En este último cabe enfatizar que las normas expedidas exigen la formación en cooperativismo y economía solidaria en la educación primaria, secundaria y media, además, en la educación superior y la formación obligatoria de todos los trabajadores asociados, dentro de los tres primeros meses a la vinculación a la cooperativa.

Con este recorrido normativo se pretende generar una visión panorámica del cooperativismo y compilar las principales leyes en torno a uno de los sectores más importantes de la economía, que proyectan el emprendimiento y la innovación, generando nuevas empresas y convirtiéndose en un instrumento para el desarrollo de los sectores más vulnerables, en el escenario del posconflicto para la construcción de la paz y de este modo se cumple el primer objetivo del proyecto de investigación, en relación con la construcción de un estado del arte, desde el punto de vista legislativo sobre el cooperativismo como antecedentes históricos.

\section{Referencias bibliográficas}

Benecke, D. W., Boettcher, E. et al. (1992). Cooperativismo, instrumento de desarrollo en un orden libre. Bogotá: Ascoop.

Congreso de Colombia. (17 de enero de 1991). Ley 9 de 1991. "Por la cual se dictan normas generales a las que deberá sujetarse el Gobierno Nacional para regular los cambios internacionales y se adoptan medidas complementarias". Recuperado de https://www.funcionpublica.gov.co/ eva/gestornormativo/norma.php?i=80013

Congreso de Colombia. (23 de diciembre 1993). Ley 101 de 1993. "Ley General de Desarrollo Agropecuario y Pesquero". Recuperado de https://www.funcionpublica.gov.co/eva/ gestornormativo/norma.php?i=66787

Congreso de Colombia. (5 de enero de 1993). Ley 35 de 1993. "Por la cual se dictan normas generales y se señalan en ellas los objetivos y criterios a los cuales debe sujetarse el Gobierno Nacional para regular las actividades financiera, bursátil y aseguradora y cualquier otra relacionada con el manejo, aprovechamiento e inversión de recursos captados del público y se dictan otras disposiciones en materia financiera y aseguradora". Recuperado de https://www. funcionpublica.gov.co/eva/gestornormativo/norma.php?i=6694

Congreso de Colombia. (28 de octubre 1993). Ley 80 de 1993. "Por la cual se expide el Estatuto General de Contratación de la Administración Pública". Recuperado de http://www. secretariasenado.gov.co/senado/basedoc/ley_0080_1993.html

Congreso de Colombia. (23 de diciembre de 1993). Ley 100 de 1993. "Por la cual se crea el sistema de seguridad social integral y se dictan otras disposiciones". Recuperado de http:// www.secretariasenado.gov.co/senado/basedoc/ley_0100_1993.html

Congreso de Colombia. (10 de diciembre de 1993). Ley 89 de 1993. "Por la cual se establece la Cuota de Fomento Ganadero y Lechero y se crea el Fondo Nacional del Ganado". Recuperado de http://www.secretariasenado.gov.co/senado/basedoc/ley_0089_1993.html 
Congreso de Colombia. (3 de noviembre de 1993). Ley 82 de 1993. "Por la cual se expiden normas para apoyar de manera especial a la mujer cabeza de familia”. Recuperado de http:// www.secretariasenado.gov.co/senado/basedoc/ley_0082_1993.html

Congreso de Colombia. (30 de diciembre de 1993). Ley 105 de 1993. "Por la cual se dictan disposiciones básicas sobre el transporte, se redistribuyen competencias y recursos entre la Nación y las Entidades Territoriales, se reglamenta la planeación en el sector transporte y se dictan otras disposiciones". Recuperado de http://www.secretariasenado.gov.co/senado/ basedoc/ley_0105_1993.html

Congreso de Colombia. (19 de agosto de 1993). Ley 65 de 1993. “Por la cual se expide el Código Penitenciario y Carcelario". Recuperado de http://www.secretariasenado.gov.co/senado/ basedoc/ley_0065_1993.html

Congreso de Colombia. (23 de mayo de 1993). Ley 41 de 1993. "Por la cual se organiza el subsector de adecuación de tierras y se establecen sus funciones". Recuperado de http://www. secretariasenado.gov.co/senado/basedoc/ley_0041_1993.html

Congreso de Colombia. (6 de enero de 1993). Ley 37 de 1993. "Por la cual se regula la prestación del servicio de telefonía móvil celular, la celebración de contratos de sociedad y de asociación en el ámbito de las telecomunicaciones y se dictan otras disposiciones". Recuperado de http:// www.secretariasenado.gov.co/senado/basedoc/ley_0037_1993.html

Congreso de Colombia. (8 de febrero de 1994). Ley 115 de 1994. "Por la cual se expide la Ley general de educación”. Recuperado de http://www.secretariasenado.gov.co/senado/basedoc/ ley_0115_1993.html

Congreso de Colombia. (11 de julio de 1994). Ley 142 de 1994. "Por la cual se establece el régimen de los servicios públicos domiciliarios y se dictan otras disposiciones". Recuperado de http://www.secretariasenado.gov.co/senado/basedoc/ley_0082_1993.html

Congreso de Colombia. (9 de febrero de 1994). Ley 118 de 1994. "Por la cual se establece la cuota de fomento hortofrutícola, se crea un fondo de fomento, se establecen normas para su recaudo y administración y se dictan otras disposiciones". Recuperado dehttp://www. secretariasenado.gov.co/senado/basedoc/ley_0082_1993.html

Congreso de Colombia. (13 de julio de 1994). Ley 146 de 1994. "Por medio de la cual se aprueba la "Convención Internacional sobre la Protección de los Derechos de todos los Trabajadores Migratorios y de sus Familiares”, hecha en Nueva York el 18 de diciembre de 1990". Recuperado de http://www.secretariasenado.gov.co/senado/basedoc/ley_0082_1993.html

Congreso de Colombia. (3 de agosto de 1994). Ley 160 de 1994. "Por la cual se crea el Sistema Nacional de Reforma Agraria y Desarrollo Rural Campesino, se establece un subsidio para la adquisición de tierras, se reforma el Instituto Colombiano de la Reforma Agraria y se dictan otras disposiciones". Recuperado de http://www.secretariasenado.gov.co/senado/basedoc/ ley_0082_1993.html 
Congreso de Colombia.(11 de julio de 1994). Ley 143 de 1994. “Por la cual se establece el régimen para la generación, interconexión, trasmisión, distribución y comercialización de electricidad en el territorio nacional, se conceden unas autorizaciones y se dictan otras disposiciones en materia energética”. Recuperado de http://www.secretariasenado.gov.co/senado/basedoc/ ley_0082_1993.html

Congreso de Colombia. (3 de agosto de 1994). Ley 161 de 1994. "Por la cual se organiza la Corporación Autónoma Regional del Río Grande de la Magdalena, se determinan sus fuentes de financiación y se dictan otras disposiciones". Recuperado de http://www.secretariasenado.gov. co/senado/basedoc/ley_0082_1993.html

Congreso de Colombia. (2 de junio de 1995). Ley 188 de 1995. "Plan Nacional de Desarrollo e Inversiones 1995 -1998". Recuperado de http://www.secretariasenado.gov.co/senado/ basedoc/ley_0082_1993.html

Congreso de Colombia. (20 de diciembre de 1995). Ley 223 de 1995. "Por la cual se expiden normas sobre Racionalización Tributaria y se dictan otras disposiciones”. Recuperado de http:// www.secretariasenado.gov.co/senado/basedoc/ley_0082_1993.html

Congreso de Colombia. (20 de diciembre de 1995). Ley 226 de 1995. "Por la cual se desarrolla el artículo 60 de la Constitución Política en cuanto a la enajenación de la propiedad accionaria estatal, se toman medidas para su democratización y se dictan otras disposiciones". Recuperado de http://www.secretariasenado.gov.co/senado/basedoc/ley_0082_1993.html

Congreso de Colombia. (28 de julio de 1995). Ley 201 de 1995. "Por la cual se establece la estructura y organización de la Procuraduría General de la Nación, y se dictan otras disposiciones". Recuperado de http://www.secretariasenado.gov.co/senado/basedoc/ley_0082_1993.html

Congreso de Colombia. (14 de marzo de 1996). Ley 272 de 1996. "Por la cual se crea la cuota de fomento porcino y se dictan normas sobre su recaudo y administración “. Recuperado de http:// www.secretariasenado.gov.co/senado/basedoc/ley_0082_1993.html

Congreso de Colombia. (23 de enero de 1996). Ley 262 de 1996. "Por la cual se autoriza a algunas cooperativas financieras para acceder a los recursos del Fondo para el Financiamiento del Sector Agropecuario -FINAGRO-y se dictan normas generales, objetivos y criterios a los cuales debe sujetarse el Gobierno Nacional para la intervención de estas entidades. Recuperado de http://www.secretariasenado.gov.co/senado/basedoc/ley_0082_1993.html

Congreso de Colombia. (10 de julio de 1997). Ley 383 de 1997. "Por la cual se expiden normas tendientes a fortalecer la lucha contra la evasión y el contrabando, y se dictan otras disposiciones". Recuperado de http://www.secretariasenado.gov.co/senado/basedoc/ley_0082_1993.html

Congreso de Colombia. (2 de agosto de 1997). Ley 395 de 1997. "Por la cual se declara de interés social nacional y como prioridad sanitaria la erradicación de la fiebre aftosa en todo el territorio colombiano y se dictan otras medidas encaminadas a este fin". Recuperado de http:// www.secretariasenado.gov.co/senado/basedoc/ley_0082_1993.html 
Congreso de Colombia. (16 de enero de 1997). Ley 347 de 1997. "Por medio de la cual se aprueban las Recomendaciones 171 sobre los servicios de Salud en el Trabajo; 172 sobre la utilización del asbesto en condiciones de seguridad; 173 sobre el bienestar de la gente de mar en el mar y en puerto; 174 sobre la repatriación de la gente de mar; 176 sobre el fomento del empleo y la protección contra el desempleo; 178 sobre el trabajo nocturno; 179 sobre las condiciones de trabajo en los hoteles, restaurantes y establecimientos similares y 180 sobre la protección de los créditos laborales en caso de insolvencia del empleador, adoptadas por la Conferencia General de la Organización Internacional del Trabajo". Recuperado de http://www. secretariasenado.gov.co/senado/basedoc/ley_0082_1993.html

Congreso de Colombia. (19 de febrero de 1997). Ley 363 de 1997. "Por medio de la cual se reforma la Ley número 132 de 1994, estatuto orgánico de los fondos ganaderos”. Recuperado de http://www.secretariasenado.gov.co/senado/basedoc/ley_0082_1993.html

Congreso de Colombia. (21 de febrero de 1997). Ley 365 de 1997. "Por la cual se establecen normas tendientes a combatir la delincuencia organizada y se dictan otras disposiciones". Colombia. Recuperado de http://www.secretariasenado.gov.co/senado/basedoc/ley_0082_1993.html

Congreso de Colombia. (9 de julio de 1997). Ley 378 de 1997. "Por medio de la cual se aprueba el "Convenio número 161, sobre los servicios de salud en el trabajo" adoptado por la 71 Reunión de la Conferencia General de la Organización Internacional del Trabajo, OIT, Ginebra, 1985". Recuperado de http://www.secretariasenado.gov.co/senado/basedoc/ley_0082_1993.html

Congreso de Colombia. (4 de julio de 1997). Ley 375 de 1997. "Por la cual se crea la Ley de la juventud y se dictan otras disposiciones “. Recuperado de http://www.secretariasenado.gov.co/ senado/basedoc/ley_0082_1993.html

Congreso de Colombia. (4 de agosto de 1998). Ley 454 de 1998. "Por la cual se determina el marco conceptual que regula la economía solidaria”. Recuperado de http://www.secretariasenado.gov. co/senado/basedoc/ley_0082_1993.html

Congreso de Colombia. (7 de febrero de 1998). Ley 436 de 1998. "Por medio de la cual se aprueba el Convenio 162 sobre Utilización del Asbesto en Condiciones de Seguridad”, adoptado en la 72a. Reunión de la Conferencia General de la Organización Internacional del Trabajo, Ginebra 1986". Recuperado de http://www.secretariasenado.gov.co/senado/basedoc/ ley_0082_1993.html

Congreso de Colombia. ( 3 de agosto de 1999). Ley 510 de 1999. "Por la cual se dictan disposiciones en relación con el sistema financiero y asegurador, el mercado público de valores, las Superintendencias Bancaria y de Valores y se conceden unas facultades". Recuperado de http://www.secretariasenado.gov.co/senado/basedoc/ley_0082_1993.html

Congreso de Colombia. (11 de noviembre de 1999). Ley 534 de 1999. "Por la cual se establece la Cuota de Fomento para la Modernización y Diversificación del Subsector Tabacalero y se dictan otras disposiciones". Recuperado de http://www.secretariasenado.gov.co/senado/basedoc/ ley_0082_1993.html 
Congreso de Colombia. (30 de diciembre de 1999). Ley 550 de 1999. "Por la cual se establece un régimen que promueva y facilite la reactivación empresarial y la reestructuración de los entes territoriales para asegurar la función social de las empresas y lograr el desarrollo armónico de las regiones y se dictan disposiciones para armonizar el régimen legal vigente con las normas de esta Ley". Recuperado de http://www.secretariasenado.gov.co/senado/basedoc/ley_0082_1993. html

Congreso de Colombia. (23 de diciembre de 1999). Ley 547 de 1999. "Por la cual se decreta el Presupuesto de Rentas y Recursos de Capital y Ley de Apropiaciones para la Vigencia Fiscal del 10. de enero al 31 de diciembre del 2000". Recuperado de http://www.secretariasenado.gov. co/senado/basedoc/ley_0082_1993.html

Congreso de Colombia. (23 de diciembre 1999). Ley 546 de 1999. "Por la cual se dictan normas en materia de vivienda, se señalan los objetivos y criterios generales a los cuales debe sujetarse el Gobierno Nacional para regular un sistema especializado para su financiación, se crean instrumentos de ahorro destinado a dicha financiación, se dictan medidas relacionadas con los impuestos y otros costos vinculados a la construcción y negociación de vivienda y se expiden otras disposiciones". Recuperado de http://www.secretariasenado.gov.co/senado/basedoc/ ley_0082_1993.html

Congreso de Colombia. (29 de julio de 1999). Ley 508 de 1999. "Por la cual se expide el Plan Nacional de Desarrollo para los años de 1999-2002". Recuperado de http://www. secretariasenado.gov.co/senado/basedoc/ley_0082_1993.html

Congreso de Colombia. (4 de agosto de 1999). Ley 517 de 1999. "Por medio de la cual se aprueba el "Acuerdo de cooperación para la prevención, control y represión del lavado de activos derivado de cualquier actividad ilícita entre el Gobierno de la República de Colombia y el Gobierno de la República del Paraguay", hecho en Santa Fe de Bogotá, D. C., el treinta y uno (31) de julio de mil novecientos noventa y siete (1997)". Recuperado de http://www.secretariasenado.gov.co/ senado/basedoc/ley_0082_1993.html

Congreso de Colombia. (29 de diciembre de 2000). Ley 633 de 2000. "Por la cual se expiden normas en materia tributaria, se dictan disposiciones sobre el tratamiento a los fondos obligatorios para la vivienda de interés social y se introducen normas para fortalecer las finanzas de la Rama Judicial". recuperado de http://www.secretariasenado.gov.co/senado/basedoc/ ley_0082_1993.html

Congreso de Colombia. ( 6 de octubre de 2000). Ley 617 de 2000. "Por la cual se reforma parcialmente la Ley 136 de 1994, el Decreto Extraordinario 1222 de 1986, se adiciona la Ley Orgánica de Presupuesto, el Decreto 1421 de 1993, se dictan otras normas tendientes a fortalecer la descentralización, y se dictan normas para la racionalización del gasto público nacional". Recuperado de http://www.secretariasenado.gov.co/senado/basedoc/ley_0082_1993.html

Congreso de Colombia. (27 de diciembre de 2000). Ley 628 de 2000. "Por la cual se decreta el Presupuesto de Rentas y Recursos de Capital y Ley de Apropiaciones para la vigencia fiscal del 10. de enero al 31 de diciembre de 2001". Recuperado de http://www.secretariasenado.gov.co/ senado/basedoc/ley_0082_1993.html 
Congreso de Colombia. (15 de agosto de 2001). Ley 685 de 2001. "Por la cual se expide el Código de Minas y se dictan otras disposiciones”. Recuperado de http://www.secretariasenado. gov.co/senado/basedoc/ley_0082_1993.html

Congreso de Colombia. (27 de diciembre de 2001). Ley 726 de 2001. "Por medio de la cual se modifican algunos artículos de la Ley 118 de 1994". Recuperado de http://www. secretariasenado.gov.co/senado/basedoc/ley_0082_1993.html

Congreso de Colombia. (20 de diciembre de 2001). Ley 714 de 2001. "Por la cual se decreta el Presupuesto de Rentas y Recursos de Capital y Ley de Apropiaciones para la vigencia fiscal del 10. de enero al 31 de diciembre de 2002". Recuperado de http://www.secretariasenado.gov. co/senado/basedoc/ley_0082_1993.html

Congreso de Colombia. (30 de julio de 2001). Ley 674 de 2001. "Por medio de la cual se aprueba el "Acuerdo de Cooperación para la prevención, control y represión del Lavado de Activos derivados de cualquier actividad ilícita entre el Gobierno de la República de Colombia y el Gobierno de la República Dominicana”, hecho en Santo Domingo, el 27 de junio de 1998". Colombia. Recuperado de http://www.secretariasenado.gov.co/senado/basedoc/ley_0082_1993.html

Congreso de Colombia. (27 de diciembre de 2002). Ley 789 de 2002. "Por la cual se dictan normas para apoyar el empleo y ampliar la protección social y se modifican algunos Artículos del Código Sustantivo de Trabajo". Recuperado de http://www.secretariasenado.gov.co/senado/ basedoc/ley_0082_1993.html

Congreso de Colombia. (29 de diciembre de 2003). Ley 863 de 2003. "Por la cual se establecen normas tributarias, aduaneras, fiscales y de control para estimular el crecimiento económico y el saneamiento de las finanzas públicas". Recuperado de http://www.secretariasenado.gov.co/ senado/basedoc/ley_0082_1993.html

Congreso de Colombia. (26 de junio de 2003). Ley 811 de 2003. "Por medio de la cual se modifica la Ley 101 de 1993, se crean las organizaciones de cadenas en el sector agropecuario, pesquero, forestal, acuícola, las Sociedades Agrarias de Transformación, SAT, y se dictan otras disposiciones". Colombia, 26 de junio de 2003. Recuperado de http://www.secretariasenado. gov.co/senado/basedoc/ley_0082_1993.html

Congreso de Colombia. (10 de julio de 2003). Ley 825 de 2003. "Por medio de la cual se aprueba el Convenio-Marco relativo a la ejecución de la Ayuda Financiera y Técnica y de la Cooperación Económica en la República de Colombia en virtud del Reglamento "ALA", firmado en Bruselas el diecisiete (17) de octubre de dos mil (2000) y en Bogotá, el catorce (14) de diciembre de dos mil (2000)". Recuperado de http://www.secretariasenado.gov.co/senado/basedoc/ ley_0082_1993.html

Congreso de Colombia. (30 de diciembre de 2004). Ley 920 de 2004. "Por la cual se autoriza a las cajas de compensación familiar adelantar actividad financiera y se dictan otras disposiciones". Recuperado de http://www.secretariasenado.gov.co/senado/basedoc/ley_0082_1993.html 
Congreso de Colombia. (21 de octubre de 2004). Ley 915 de 2004. "Por la cual se dicta el Estatuto Fronterizo para el Desarrollo Económico y Social del departamento Archipiélago de San Andrés, Providencia y Santa Catalina". Recuperado de http://www.secretariasenado.gov.co/ senado/basedoc/ley_0082_1993.html

Congreso de Colombia. (23 de diciembre de 2004). Ley 921 de 2004. "Por la cual se decreta el Presupuesto de rentas y recursos de capital y Ley de apropiaciones para la vigencia fiscal del 10 de enero al 31 de diciembre de 2005". Recuperado de http://www.secretariasenado.gov.co/ senado/basedoc/ley_0082_1993.html

Congreso de Colombia. (4 de abril de 2005) Ley 952 de 2005. "Por medio de la cual se modifica el artículo $2^{\circ}$ de la Ley 700 de 2001 y se dictan otras disposiciones”. Recuperado de http:// www.secretariasenado.gov.co/senado/basedoc/ley_0082_1993.html

Congreso de Colombia. (23 de enero de 2006). Ley 1013 de 2006. "Por la cual se modifica el artículo 14 de la Ley 115 de 1994, el artículo 2, modifica el literal d) del artículo 14, establece la educación para la Justicia, la Paz, la Democracia, la Solidaridad, la Confraternidad, la Urbanidad, el Cooperativismo y en general la formación de los valores humanos". Recuperado de http:// www.secretariasenado.gov.co/senado/basedoc/ley_0082_1993.html

Congreso de Colombia. (12 de junio de 2006). Ley 1029 de 2006. "Por la cual se modifica el artículo 14 de la Ley 115 de 1994, tipificando la enseñanza obligatoria, y dicta que: "En todos los establecimientos oficiales o privados que ofrezcan educación formal es obligatoria en los niveles de la educación preescolar, básica y media cumplir con: d) La educación para la justicia, la paz, la democracia, la solidaridad, la confraternidad, el cooperativismo y, en general, la formación de los valores humanos". Recuperado de http://www.secretariasenado.gov.co/senado/basedoc/ ley_0082_1993.html

Congreso de Colombia. (27 de diciembre 2006). Ley 1111 de 2006. "Por la cual se modifica el Estatuto Tributario de los impuestos administrados por la Dirección de Impuestos y Aduanas Nacionales, obligando a adicionar al Estatuto el artículo 462-1, el cual dispone: "Servicios gravados a la tarifa del 1.6\%. En los servicios de aseo, en los de vigilancia autorizados por la Superintendencia de Vigilancia Privada, en los de empleo temporal prestados por empresas autorizadas por el Ministerio de la Protección Social y en los prestados por las cooperativas y precooperativas de trabajo asociado en cuanto a mano de obra se refiere, vigiladas por la Superintendencia de Economía Solidaria o quien haga sus veces, a las cuales se les haya expedido resolución de registro por parte del Ministerio de la Protección Social, de los regímenes de trabajo asociado, compensaciones y seguridad social, la tarifa será del 1.6\%". Recuperado de http://www.secretariasenado.gov.co/senado/basedoc/ley_0082_1993.html

Congreso de Colombia. (29 de diciembre de 2006). Ley 1121 de 2006. "Por la cual se dictan normas para la prevención, detección, investigación y sanción de la financiación del terrorismo y otras disposiciones". Recuperado de http://www.secretariasenado.gov.co/senado/basedoc/ ley_0082_1993.html 
Congreso de Colombia. (16 de julio de 2007). Ley 1150 de 2007. "Por medio de la cual se introducen medidas para la eficiencia y la transparencia en la Ley 80 de 1993 y se dictan otras disposiciones generales sobre la contratación con Recursos Públicos". Recuperado de http:// www.secretariasenado.gov.co/senado/basedoc/ley_0082_1993.html

Congreso de Colombia. (22 de enero de 2007). Ley 1127 de 2007. "Por la cual se hacen algunas modificaciones en el Sistema General de Seguridad Social en Salud y se dictan otras disposiciones". Recuperado de http://www.secretariasenado.gov.co/senado/basedoc/ ley_0082_1993.html

Congreso de Colombia. (30 de abril de 2008). Ley 1190 de 2008. "Por medio de la cual el Congreso de Colombia declara el 2008 como el año de la promoción de los derechos de las personas desplazadas por la violencia y se dictan otras disposiciones". Recuperado de http:// www.secretariasenado.gov.co/senado/basedoc/ley_0082_1993.html

Congreso de Colombia. (4 de diciembre de 2008). Ley 1257 de 2008. "Por la cual se dictan normas de sensibilización, prevención y sanción de formas de violencia y discriminación contra las mujeres, se reforman los Códigos Penal, de Procedimiento Penal". Recuperado de http:// www.secretariasenado.gov.co/senado/basedoc/ley_0082_1993.html

Congreso de Colombia. (22 de julio de 2008). Ley 1233 de 2008. "Por medio de la cual se precisan los elementos estructurales de las contribuciones a la seguridad social, se crean las contribuciones especiales a cargo de las Cooperativas y Precooperativas de Trabajo Asociado, con destino al Servicio Nacional de Aprendizaje, Sena, al Instituto Colombiano de Bienestar Familiar, ICBF, y a las Cajas de Compensación Familiar, se fortalece el control concurrente y se dictan otras disposiciones". Recuperado de http://www.secretariasenado.gov.co/senado/ basedoc/ley_0082_1993.html

Congreso de Colombia. (12 de noviembre de 2009). Ley 1357 de 2009. "Por la cual se modifica el Código Penal, que establece como delito la omisión de control, en la administración de cooperativas del sector financiero (art. 325)". Recuperado de http://www.secretariasenado.gov. co/senado/basedoc/ley_0082_1993.html

Congreso de Colombia. (31 de julio de 2009). Ley 1346 de 2009. "Por medio de la cual se aprueba la "Convención sobre los Derechos de las personas con Discapacidad", adoptada por la Asamblea General de la Naciones Unidas el 13 de diciembre de 2006, que en el art. 27 sobre trabajo y empleo para las personas con discapacidad, se promueve la constitución de cooperativas como iniciativa empresarial". Colombia, 31 de julio de 2009. Recuperado de http://www.secretariasenado.gov.co/senado/basedoc/ley_0082_1993.html

Congreso de Colombia. (15 de julio de 2009). Ley 1328 de 2009. "Por la cual se dictan normas en materia financiera, de seguros, del mercado de valores y otras disposiciones, en esta norma se regulan las cooperativas de ahorro y crédito, en la prestación de servicios y de inversión de capital". Recuperado de http://www.secretariasenado.gov.co/senado/basedoc/ ley_0082_1993.html 
Congreso de Colombia. (29 de diciembre de 2010). Ley 1429 de 2010. "Por la cual se expide la Ley de Formalización y Generación de Empleo, establece descuentos tributarios para los empleadores que realicen contrataciones de jóvenes, de personas de bajos ingresos y en condición de desplazamiento". Recuperado de http://www.secretariasenado.gov.co/senado/ basedoc/ley_0082_1993.html

Congreso de Colombia. (29 de diciembre de 2010). Ley 1430 de 2010. "Por medio de la cual se dictan normas tributarias de control y para la competitividad, en esta Ley se dictan normas que incluyen las cooperativas del sector financiero, en relación con los desembolsos de créditos, retiros y créditos obtenidos en el exterior". Recuperado de http://www.secretariasenado.gov.co/ senado/basedoc/ley_0082_1993.html

Congreso de Colombia. (19 de enero de 2011). Ley 1438 de 2011. "Por medio de la cual se reforma el Sistema General de Seguridad Social en Salud y se dictan otras disposiciones". Recuperado de http://www.secretariasenado.gov.co/senado/basedoc/ley_0082_1993.html

Congreso de Colombia. (12 de julio de 2011). Ley 1474 de 2011. "Por la cual se dictan normas orientadas a fortalecer los mecanismos de prevención, investigación y sanción de actos de corrupción y la efectividad del control de la gestión pública". Recuperado de http://www. secretariasenado.gov.co/senado/basedoc/ley_0082_1993.html

Congreso de Colombia. (26 de diciembre de 2012). Ley 1607 de 2012. "Por la cual se expiden normas en materia tributaria y se dictan otras disposiciones". Recuperado de http://www. secretariasenado.gov.co/senado/basedoc/ley_0082_1993.html

Congreso de Colombia. (27 de abril de 2012). Ley 1527 de 2012. "Por medio de la cual se establece un marco general para la libranza o descuento directo y se dictan otras disposiciones". Obtenido de http://www.secretariasenado.gov.co/senado/basedoc/ley_0082_1993.html

Congreso de Colombia. (11 de julio de 2012). Ley 1562 de 2012. "Por la cual se modifica el Sistema de Riesgos Laborales y se dictan otras disposiciones en materia de Salud Ocupacional”. Recuperado de http://www.secretariasenado.gov.co/senado/basedoc/ley_0082_1993.html

Congreso de Colombia. (8 de septiembre de 2014). Ley 1739 de 2014. "Por medio de la cual se modifica el Estatuto Tributario". Recuperado de http://www.secretariasenado.gov.co/senado/ basedoc/ley_0082_1993.html

Congreso de Colombia. ( 30 de junio de 2015). Ley 1755 de 2015. "Por medio de la cual se regula el Derecho Fundamental de Petición y se sustituye un título del Código de Procedimiento Administrativo y de lo Contencioso Administrativo". Recuperado de http://www.secretariasenado. gov.co/senado/basedoc/ley_0082_1993.html

Congreso de Colombia. (2 de mayo de 2016). Ley 1780 de 2016. "Por medio de la cual se promueve el empleo y el emprendimiento juvenil, se generan medidas para superar barreras de acceso al mercado de trabajo y se dictan otras disposiciones". Recuperado de http://www. secretariasenado.gov.co/senado/basedoc/ley_0082_1993.html 
Fisher, K. (1998). ¿Qué causa la crisis de las cooperativas financieras? Revista Coopdesarrollo, 1(84), 15.

Fouquet, G. (1944). El sector cooperativo. Buenos Aires: Intercoop.

Pardo, L. P., Serrano, R. y Jaramillo, G. (2006). Estado del arte del sector solidario en Colombia. Bogotá: Editorial Universidad Cooperativa de Colombia.

Pardo-Martínez, L. P. y Huertas de Mora, M. V. (2014). La historia del cooperativismo en Colombia: hitos y periodos. Cooperativismo \& Desarrollo, 104(22), 49-61. doi: http://dx.doi.org/10.16925/ co.v22i104.970

Presidente de la República de Colombia. (1993). Decreto 663 de 1993. "Por medio del cual se actualiza el Estatuto Orgánico del Sistema Financiero y se modifica su titulación y numeración. Recuperado de http://www.supersociedades.gov.co/Web/Decreto/Decreto_663_1993.htm

Uribe, C. (2004). Crisis ideológica del cooperativismo. Bogotá: Ediciones Guadalupe, Fondo Nacional Universitario. 